REVISTA DE DERECHO UNED, núm. 6, 2010

\title{
ALGUNAS CONSIDERACIONES EN TORNO A LA EJECUCIÓN PROVISIONAL DE SENTENCIAS DICTADAS EN PROCESOS PARA LA PROTECCIÓN DE LOS DERECHOS REALES
}

\author{
María Luisa Boticario GalaVís \\ Doctora en Derecho. Profesora Ayudante de Derecho \\ Procesal de la UNED
}

Resumen: El objeto de este trabajo estriba en analizar si cabe llevar a cabo la ejecución provisional respecto de alguna de las materias recogidas en el artículo 250.1 LEC, concretamente en relación con los llamados «interdictos», así como con el proceso dirigido a la protección registral de los derechos reales inscritos.

Palabras clave: Proceso civil, ejecución provisional, interdictos, registro.

\begin{abstract}
The object of this work is to consider whether it is possible or not to carry out provisional execution on some of the matters contained in article 250. 1 LEC, specifically in relation to so-called «injunctions», as well as with the process aimed at the registral protection of the property rights inscribed.
\end{abstract}

Key words: Civil process, provisional execution, injunction, registry.

Sumario: I. Introducción.-II. La ejecución provisional en los tradicionales «interdictos».-II.1. Las demandas que pretendan retener o recobrar la posesión.-II.2. Las demandas que pretendan la suspensión de una obra nueva.-II.2.A. La sentencia estimatoria.-II.2.B. La sentencia desestimatoria.-II.3. Las demandas que, por estado ruinoso, pretendan la demolición de una obra.-II.4. Las demandas que pretendan recabar la posesión de los bienes hereditarios.-III. El procedimiento para la protección registral de los derechos reales inscritos.-IV. Conclusiones. 


\section{INTRODUCCIÓN. MARCO REGULADOR}

El marco procedimental configurado por la Ley 1/2000, de 7 de enero, de Enjuiciamiento Civil, permite distinguir entre "procesos ordinarios» $\mathrm{y}$ "procesos especiales». Los procesos ordinarios articulados para llevar a cabo la tutela judicial declarativa ${ }^{1}$ son los denominados «juicio ordinario ${ }^{2} \mathrm{y}$ «juicio verbal» ${ }^{3}$. El análisis del texto legal permite afirmar que su característica especial estriba en ser los procesos comunes en el ámbito civil, en la medida en que sus disposiciones resultan de aplicación directa, en virtud de lo dispuesto en los artículos 249 y 250 LEC, y, en cualquier caso, supletoria de los demás procedimientos especiales y sumarios, gozando, en último término, las normas del juicio ordinario del carácter de supletorias, respecto del resto de los procedimientos, incluido el juicio verbal ${ }^{4}$.

En relación con la atribución de los diversos tipos de asuntos en los distintos cauces procedimentales previstos por el legislador, el apartado X de la Exposición de Motivos de la citada norma afirma que, el juicio verbal, se reserva para aquellos litigios iniciados me-

1 Al respecto señala la Exposición del Motivos que «Estos procesos acogen, en algunos casos gracias a disposiciones particulares, los litigios que hasta ahora se ventilaban a través de cuatro procesos ordinarios, así como todos los incidentes no regulados expresamente, con lo que cabe suprimir también el procedimiento incidental común. $Y$ esta nueva Ley de Enjuiciamiento Civil permite también afrontar, sin merma de garantías, los asuntos que eran contemplados hasta hoy en más de una docena de leyes distintas de la procesal civil común. Buena prueba de ello son la disposición derogatoria y las disposiciones finales.

Así, pues, se simplifican, con estos procedimientos, los cauces procesales de muchas y muy diversas tutelas jurisdiccionales. Lo que no se hace, porque carecería de razón y sentido, es prescindir de particularidades justificadas, tanto por lo que respecta a presupuestos especiales de admisibilidad o procedibilidad como en lo relativo a ciertos aspectos del procedimiento mismo.

Lo exigible y deseable no es unificar a ultranza, sino suprimir lo que resulta innecesario y, sobre todo, poner término a una dispersión normativa a todas luces excesiva. No cabe, por otra parte, ni racional ni constitucionalmente, cerrar el paso a disposiciones legales posteriores, sino sólo procurar que los preceptos que esta Ley contiene sean, por su previsión y flexibilidad, suficientes para el tratamiento jurisdiccional de materias y problemas nuevos.

La Ley diseña los procesos declarativos de modo que la inmediación, la publicidad y la oralidad hayan de ser efectivas. En los juicios verbales, por la trascendencia de la vista; en el ordinario, porque tras demanda y contestación, los hitos procedimentales más sobresalientes son la audiencia previa al juicio y el juicio mismo, ambos con la inexcusable presencia del juzgador».

2 Vid. Artículos 399 y ss. LEC.

3 Vid. Artículos 437 y ss. LEC.

${ }^{4}$ Cfr. GIMENO SENDRA, V., Derecho Procesal Civil. II. Los procesos especiales, Editorial Colex, 2. ${ }^{a}$ edición, Madrid, 2007, p. 75. 
diante demanda sucinta con inmediata citación para la vista, que se caracterizan, de un lado, por «la singular simplicidad de lo controvertido»y, de otro «por su pequeño interés económico». En cuanto al resto de posibles litigios, quedarán sometidos al cauce procedimental del juicio ordinario, caracterizado por los principios de concentración, inmediación y oralidad. Junto a este criterio material habrá de ser tomado en consideración el dato relativo a la determinación de la cuantía.

En relación con los denominados «procesos especiales», conviene recordar que el legislador, de un lado, establece unos procesos especiales «típicos», contemplados en el Libro IV de la LEC ${ }^{5}$ y, de otro, configura una serie de procesos que pueden ser calificados como "procesos ordinarios con especialidades ${ }^{6}$, en la medida en que, si bien determinadas materias, en virtud de lo establecido en los citados artículos 249 y 250 LEC se dilucidarán respectivamente, a través de las normas del juicio ordinario o, a través de las del juicio verbal, junto a ello, deberán ser tomadas en consideración todas aquellas previsiones que, con carácter específico para materias concretas, aparecen recogidas a lo largo del articulado de la propia Ley de Enjuiciamiento Civil.

$\mathrm{Al}$ margen de estas cuestiones, debe tenerse en cuenta que, una de las principales innovaciones que trajo consigo la reforma global del proceso civil, llevada a cabo en el año 2000, fue la relativa a dotar a este proceso de una nueva regulación de la ejecución provisional (artículos 524 a 537 LEC), por la que se convierte en regla general la ejecución de las sentencias de condena dictadas, tanto en primera, como en segunda instancia, que aún no hayan alcanzado firmeza por haberse interpuesto el recurso correspondiente contra ellas.

En relación con la materia que nos ocupa, debe partirse de que tal regulación de la ejecución provisional no hace mención alguna al tipo de procedimiento en que se haya dictado una sentencia, como elemento que deba tenerse en cuenta a la hora de permitir, denegar o limitar su acceso a la ejecución provisional. Ello no obstante, estas líneas pretenden realizar un análisis de algunas materias respecto de las que, bien por su relevancia práctica, bien por la falta de una res-

${ }^{5}$ El Libro IV de la LEC contiene tres títulos: El Título I, «De los procesos sobre capacidad, filiación, matrimonio y menores», el Título II, "De la división judicial de patrimonios»y, el Título III, «De los procesos monitorio y cambiario».

${ }^{6}$ Cfr. GIMENO SENDRA, V., Derecho Procesal Civil..., op. cit., pp. 75 y 76. Vid. asismismo DE LA OLIVA SANTOS, A. y DÍEZ-PICAZO GIMÉNEZ, I., Derecho Procesal Civil. El proceso de declaración, 3. a edición, Editorial Universitaria Ramón Areces, Madrid, 2004, pp. 631 y ss. 
puesta doctrinal y jurisprudencial unánime, pueden suscitarse dudas a la hora de proceder a dicha ejecución.

\section{LA EJECUCIÓN PROVISIONAL EN LOS TRADICIONALES «INTERDICTOS»}

Aún cuando en la vigente LEC se produjo la desaparición de la tradicional mención a los «procesos sumarios», «juicios posesorios» o a los «interdictos ${ }^{7}$, debe repararse en que su diverso contenido figura recogido en la lista del artículo 250.1 LEC de manera que, tales materias se tramitarán, por razón de la materia, por las normas del juicio verbal, si bien, como se ha señalado, recogiendo el articulado de la LEC diversas reglas procesales de aplicación especial que, tomadas en su conjunto, permiten configuran una tutela sumaria de los derechos por ellas protegidos ${ }^{8}$.

Entre estas especialidades, no se encuentra mención alguna al régimen específico de la ejecución provisional, de donde se deduce que, serán el contenido y la forma de la resolución dictada en cada uno de estos procesos, los elementos que permitan o limiten la aplicación del régimen de ejecución provisional previsto en los artículos 524 y ss. LEC a las sentencias en ellos dictadas 9 .

\section{II.1. Las demandas que pretendan retener o recobrar la posesión}

Los tradicionales «interdictos de retener y de recobrar la posesión ${ }^{10}$, vienen recogidos en el artículo $250.1 .4^{\circ} \mathrm{LEC}^{11}$, refiriéndose el legislador a ellos como aquellos litigios en los que se ventilan demandas que pretenden «la tutela sumaria de la tenencia o de la pose-

\footnotetext{
7 Estos procesos venían contemplados en los artículos 1631 y ss. de la LEC/1881.

8 Vid. ARMENTA DEU, T., La ejecución provisional, Editorial La Ley, Madrid, 2000, p. 147.

9 Sobre la regulación de esta materia en la legislación anterior, Vid. PÉREZ GORDO, A., La ejecución provisional en el proceso civil, Librería Bosch, Barcelona, 1973 y CABALLOL ANGELATS, L., La ejecución provisional en el proceso civil, José María Bosch editor, S.A., Barcelona, 1993.

10 En relación con estos procesos, se ha criticado que «desgraciadamente» haya desaparecido el término tradicional de «interdictos». Cfr. Auto de la Audiencia Provincial de Madrid (Sección 14ª), Auto núm. 68/2004 de 10 marzo, JUR 2004\249277, Razonamiento Jurídico Tercero.

${ }^{11}$ Cabe destacar que el legislador no los ha regulado separadamente, como ha hecho con los juicios de obra nueva y de obra ruinosa, en los apartados $5^{\circ}$ y $6^{\circ}$ del artículo 250.1 LEC. Cfr. GIMENO SENDRA, V., Derecho Procesal Civil..., op. cit., p. 81.
} 
sión de una cosa o derecho por quien haya sido despojado de ellas o perturbado en su disfrute» ${ }^{12}$.

El objeto de estos procesos viene constituido por la perturbación o despojo que recae sobre cosas o bienes del Derecho privado, así como sobre los derechos reales e incluso personales susceptibles de la posesión ${ }^{13}$.

De este modo, su finalidad estriba en lograr impedir que se altere una situación de hecho, sin el necesario concurso de un pronunciamiento judicial o la voluntad conforme de los interesados, por mantenerse el fundamento sustantivo de la protección posesoria en los artículos 441 y 446 del Código Civil, según los cuales, en ningún caso puede adquirirse violentamente la posesión mientras exista un poseedor que se oponga a ello, quien tiene derecho a ser respetado en su posesión pudiendo, tanto el que se crea con acción o derecho para privar a otro de la tenencia de una cosa, como el que fuera inquietado en ella, solicitar el auxilio judicial para ser amparados en su derecho ${ }^{14}$.

Desde otro punto de vista, debe tenerse en cuenta que las pretensiones ventiladas en estos procesos gozan de un carácter mixto, habida cuenta que, de un lado, se trata de una pretensión declarativa, dirigida a obtener el reconocimiento del goce pacífico de la posesión de hecho y, de otro, una pretensión de condena.

Esta pretensión condenatoria será diferente según se trate de una demanda dirigida a recobrar, en cuyo caso la sentencia condenará al demandado a la restitución de la posesión, mientras que en el supuesto de la demanda dirigida a retener, dará lugar a una condena en la que se ordene el mantenimiento del demandante en la posesión, apercibiendo al demandado para que se abstenga de realizar en lo sucesivo los actos de perturbación, así como al pago de las costas ${ }^{15}$.

12 El artículo 439.1 LEC se refiere a esta materia con la expresión «demandas que pretendan retener o recobrar la posesión».

13 Cfr. GIMENO SENDRA, V., Derecho Procesal Civil..., op. cit., p. 82.

${ }^{14}$ Cfr. Audiencia Provincial de Barcelona (Sección 13a), Auto núm. 129/2008 de 25 abril, JUR 2008\178251, Razonamiento Jurídico Primero. La Audiencia, con cita de la Sentencia del Tribunal Supremo de 30 de septiembre de 2005, reitera en el citado Auto que «la protección interdictal responde a la necesidad de mantener el «statu quo» $y$, al fin, la paz social ante actos de propia autoridad, impidiendo que una situación existente, de hecho o aparente, sea atacada ni siquiera por quien puede oponer un derecho contrario; y que en consecuencia el objeto del interdicto no es otro que la posesión ("ius possessionis"), como poder de hecho, con independencia de que el poseedor tenga derecho o no a seguir siéndolo ("ius possidendi")».

15 Cfr. ARMENTA DEU, T., La ejecución provisional, op. cit., p. 148; GIMENO SENDRA, V., Derecho Procesal Civil. Tomo II. Los procesos especiales, op. cit., p. 94. 
La sentencia dictada en estos procesos, tanto estimatoria, como desestimatoria, será susceptible del recurso de apelación, habida cuenta que al respecto no hay previsión específica alguna y, por tanto, quedan sometidas al régimen común de los recursos, previsto en los artículos 448 y ss. LEC.

Desde el punto de vista de su posible ejecución provisional, debe entenderse que, en la medida en que la Ley procesal no incluye tampoco previsión alguna entre las previsiones específicas del juicio verbal respecto de la tutela sumaria de la tenencia o de la posesión de una cosa o derecho por quien haya sido despojado de ellas o perturbado en su disfrute, a mi juicio, debe entenderse que el régimen aplicable a las sentencias dictadas en relación con esta materia, será el régimen general establecido en los artículos 524 y ss. LEC ${ }^{16}$.

Esta conclusión se justifica, igualmente, en la medida en que las sentencias de condena relativas a la pretensión de retener o recobrar la posesión prevista en el artículo 250.1.4 ${ }^{\circ}$ LEC, no figuran incluidas entre las excepciones recogidas por el artículo 525 LEC, por lo que, efectivamente, resultarán provisionalmente ejecutables ${ }^{17}$.

En este mismo sentido se han pronunciado nuestros Tribunales. Así, la Audiencia Provincial de Barcelona ${ }^{18}$, en un proceso en el que se solicitaba la ejecución provisional de una sentencia dictada en relación con una pretensión de recobrar la posesión, por la que se ordenaba al demandado que repusiera al demandante en la posesión de un huerto en una planta baja de una finca, demoliendo la valla instalada y reponiendo la valla existente entre los bajos y el huerto, la Audiencia estimó procedente la ejecución provisional solicitada, al considerar que no se trataba de una sentencia meramente declarativa, sino de una sentencia de condena que contenía una obligación de hacer, consistente en el restablecimiento del estado de hecho preexistente y, que había sido perturbado, resultando irrelevante para el citado órgano judicial, que dicha sentencia hubiera sido dictada en un procedimiento sumario ${ }^{19}$.

16 Cfr. ARMENTA DEU, La ejecución provisional, op. cit., p. 149.

17 Vid. en este sentido, Auto de la Audiencia Provincial de Madrid (Sección 14ª), Auto núm. 68/2004 de 10 marzo, JUR 2004\249277. Razonamiento Jurídico Tercero.

Cfr. Auto Audiencia Provincial de Barcelona (Sección 13a), Auto núm. 129/2008 de 25 abril, JUR $2008 \backslash 178251$, Razonamiento Jurídico Primero.

${ }_{19}$ La Audiencia afirma que «resulta un absurdo jurídico que el vencedor en el pleito para la tutela sumaria de la posesión, no pueda obtener esa tutela sumaria hasta después de haber vencido en un proceso declarativo ordinario posterior, lo cual convierte en completamente inútil el proceso interdictal». Cfr. Audiencia Provincial de Barcelona (Sección 13 ${ }^{\mathrm{a}}$ ), Auto núm. 129/2008 de 25 abril, JUR\2008\178251, Razonamiento Jurídico Primero. 


\section{II.2. Las demandas que pretendan la suspensión de una obra nueva}

La LEC recoge en los artículos $250.1 .5^{\circ}$ y 441.2 LEC, como especialidad del juicio verbal, aquellas demandas, cualquiera que sea su cuantía, "que pretendan que el tribunal resuelva, con carácter sumario, la suspensión de una obra nueva», coincidiendo, por tanto, con el denominado tradicionalmente «interdicto de obra nueva».

Siguiendo a GIMENO ${ }^{20}$, cabe distinguir, dentro de la fines perseguidos por este proceso, de un lado, una finalidad genérica, cual es la de impedir los irreparables daños que pudieran producirse a la definitiva construcción de una obra, y, de otro, una finalidad inmediata que consiste en obtener su suspensión o paralización.

Todo ello implica efectivamente que, a través de este proceso, no se pueda obtener la condena a la demolición de una obra ilícitamente realizada. Dicha finalidad podría perseguirse mediante el juicio declarativo plenario correspondiente o, a través del juicio verbal para recobrar la posesión, pero, en ningún caso, mediante el de obra nueva que se dirige única y exclusivamente a obtener del Juez una resolución de paralización o suspensión de las obras.

En esta materia concreta, tiene una especial trascendencia la previsión realizada por el artículo 441.2 LEC, en cuya virtud, en aquellos procesos en los que se pretenda que, con carácter sumario, se resuelva judicialmente la suspensión de una obra nueva, el Tribunal, antes incluso de la citación para la vista, dirigirá inmediata orden de suspensión al dueño o encargado de la obra. Ello no obstante, el citado precepto prevé, a continuación, que el demandado pueda ofrecer caución para continuar la obra, así como la realización de obras indispensables para conservar lo ya edificado.

\section{II.2.A. La sentencia estimatoria}

Teniendo en cuenta lo anterior, el contenido de la sentencia estimatoria, dictada en el juicio verbal de obra nueva, supondrá una orden de suspensión dirigida al dueño de la obra o la ratificación de la suspensión provisional, si ya había sido acordada ${ }^{21}$ y su conversión en definitiva.

${ }^{20}$ Cfr. GIMENO SENDRA, V., Derecho Procesal Civil..., op. cit., pp. 100-101. Vid. igualmente ACHÓN BRUÑEN, M. J., La ejecución civil. Problemática general. 344 preguntas y respuestas, Editorial Sepín, Madrid, 2008, p. 109.

${ }^{21}$ Cfr. ARMENTA DEU, La ejecución provisional, op. cit., p. 149; GIMENO SENDRA, V., Derecho Procesal Civil..., op. cit., p. 104. 
Al igual que en el supuesto anterior, habida cuenta que la LEC 1/2000, al contrario que la LEC/1881 ${ }^{22}$, no establece una regulación específica respecto a los medios de impugnación, ni a sus efectos, ni a su ejecución, la sentencia que estima la pretensión de suspensión de obra habrá de regirse por las normas generales de la previstas en la LEC sobre estas materias. Por tanto, en aplicación de la previsión contenida en el artículo 455.1 LEC, cabe, sin duda alguna, la interposición del recurso de apelación.

Igualmente, en la medida en que se trata de una sentencia de condena, concretamente de no hacer, y que no figura comprendida en los casos previstos en el artículo 525 LEC, cabe sostener, al menos desde un punto de vista teórico, que no hay impedimento legal alguno para aceptar su ejecución provisional. Dicha ejecución consistiría, bien en suspender la obra, bien en mantener la suspensión ya practicada, durante la tramitación del recurso de apelación, en virtud del contenido del artículo 456.3 LEC.

En el supuesto de que el constructor hubiera logrado la continuación de la obra, mediante la prestación de la caución a que, como se ha reiterado, hace referencia el artículo 441.2 LEC, la posible sentencia estimatoria, además de ordenar la suspensión de la obra, deberá condenar a indemnizar al actor por los daños y perjuicios que haya podido padecer.

No obstante las consideraciones anteriores, debe repararse en que, desde una perspectiva práctica resulta ciertamente más adecuado el criterio mantenido por los Tribunales, en el sentido de considerar que no debe despacharse ejecución provisional respecto de una sentencia de suspensión de obra nueva. El fundamento de tal negativa estriba en que, tal resolución es directamente ejecutiva desde el momento de admisión a trámite de la demanda, de tal manera que, su ejecutividad se producirá en el proceso declarativo, sin necesidad de instar la ejecución provisional.

En esta línea se pronunció la Audiencia Provincial de Valencia ${ }^{23}$, al afirmar que, a pesar de que la sentencia que decide la tutela sumaria de obra nueva no figure comprendida en el artículo 525 LEC

\footnotetext{
${ }^{22}$ Vid. artículos 1.669 a 1.674 LEC/1881. De conformidad con este régimen, el demandado podía iniciar un procedimiento declarativo en reconocimiento de su derecho a continuar la obra e iniciar un procedimiento incidental, al mismo tiempo o con posterioridad a la demanda principal («ex» artículo 1.671, en relación con el artículo 1672.2 $2^{\circ}$, ambos de la LEC/1881).

${ }^{23}$ Cfr. Audiencia Provincial de Valencia (Sección 11 ${ }^{\text {a }}$ ). Auto núm. 129/2007 de 28 mayo, JUR\2007 260279, Fundamento Jurídico Segundo.
} 
como no provisionalmente ejecutable, no es susceptible de tal medida porque, estrictamente, no contiene un pronunciamiento de condena a favor del solicitante, sino que se limita a ratificar la decisión de suspensión adoptada al inicio del proceso, concretamente al admitir a trámite la propia demanda de suspensión de la obra nueva, «ex» artículo 441.2 LEC. Para el Tribunal, la sentencia dictada, aún implicando una orden de no hacer, no la decide por si misma.

Incide en esta línea la Audiencia con el siguiente argumento: «Siendo particularidad del juicio verbal de suspensión de la obra nueva el que se adopta la inmediata tutela sumaria de esta clase cuando se admite a trámite la demanda (artículo 441-2 $2^{\circ}$ de la LEC), resultando ejecutiva y pudiendo quebrantarse desde ese mismo momento la orden judicial, y siendo factible que se insten las medidas oportunas para salvar este situación dentro del mismo trámite declarativo que se sigue, correspondiendo actuar en este caso, de forma equivalente a lo que dispone el artículo 710 de la LEC, y sin necesidad, por tanto, de demanda de ejecución provisional de la sentencia, puesto que lo que se debe decidir es si se ha quebrantado la orden comprendida en el auto inicial tal y como se ha ejecutado, y no la sentencia que eventualmente la ratifica. Siendo, en resumen, lo relevante, la ejecutividad inicial de la orden de suspensión de la obra nueva, que es la que puede quebrantar la demandada, más que la propia sentencia que posteriormente se dicte, no obstante su relevancia cuando alcance firmeza, porque mientras tanto no queda privada aquella orden de sus efectos $»^{24}$.

Por tanto, aún siendo teóricamente susceptible de ejecución provisional, debe entenderse que tal ejecución no se llevará a cabo, en la medida en que no resulta necesaria. Efectivamente, si la suspensión de la obra fue acordada desde el inicio del procedimiento «ex» artículo 441.2 LEC y, la posterior sentencia estimatoria de la pretensión de suspensión es recurrida, no debiera exigirse, a pesar de que la Ley no lo establezca expresamente, la interposición de una posterior demanda instando su ejecución provisional para lograr el man-

${ }^{24}$ Continúa el argumento de la Audiencia en los siguientes términos: «Debiendo tenerse también en cuenta que el artículo 710 de la LEC contempla respecto a las condenas de no hacer, tras la constatación del quebrantamiento de condena por parte del Juzgador, el requerimiento judicial, a instancia del ejecutante, para que el ejecutado deshaga lo mal hecho si fuere posible, indemnice los daños y perjuicios causados y, en su caso, se abstenga de reiterar el quebrantamiento, con apercibimiento de incurrir en delito de desobediencia a la autoridad judicial. El que se deba proceder de esta forma cuantas veces se incumpla la condena-en este caso la orden de no hacer-. Y permitiendo dicho precepto, igualmente, la intimación con imposición de multas para que deshaga lo mal hecho por cada mes que transcurra sin deshacerlo». 
tenimiento de aquella suspensión acordada previamente, hasta el momento en que se dicte sentencia firme ${ }^{25}$.

\section{II.2.B. La sentencia desestimatoria}

En el supuesto de que la pretensión de suspensión de la obra resulte desestimada, la sentencia dictada en primera instancia implicará la continuación de la obra, de manera que, si la suspensión fue acordada con base la previsión efectuada por el citado artículo 441.2 LEC, deberá llevarse a cabo su alzamiento definitivo.

En este caso, la posible interposición del recurso de apelación por el demandante vencido, no afectará a la ejecución de la obra, pues la apelación contra sentencias desestimatorias, en virtud del contenido del artículo 456.2 LEC, no produce efectos suspensivos.

Precisamente esta ausencia de efectos suspensivos es la que conduce a la conclusión respecto de la improcedencia de la ejecución provisional de la sentencia recurrida, sin perjuicio de que, en el supuesto de que el demandante-recurrente pretenda que continúe la suspensión de la obra durante la sustanciación del recurso, pueda solicitarlo como medida cautelar ante el Tribunal que conozca del mismo ${ }^{26}$.

25 Vid. ACHÓN BRUÑEN, La ejecución civil. Problemática general. 344 preguntas y respuestas, op. cit., p. 109. Según esta autora, «de acatar estrictamente la literalidad legal y, considerar que la interposición del recurso no permite hacer efectivo el fallo, pudiera inferirse que la suspensión debe alzarse cuando se dicte sentencia estimatoria que sea recurrida; sin embargo, dicha interpretación resulta contraria a la propia "ratio essendi» que rige en este tipo de juicios de tutela sumaria de la posesión, en donde aun antes de la celebración de la vista, y en aras de evitar mayores perjuicios, se acuerda la suspensión de la obra — que tan sólo se permite continuar cuando el Juez expresamente lo acuerde previa prestación de caución o para conservar lo edificado-, por lo que una vez. dictada sentencia a favor del actor, resultaría un contrasentido dejar a éste en peor situación que lo estaba con anterioridad, alzando la suspensión de la obra si la sentencia fuere recurrida, ya que se le compelería en todo caso a tener que presentar una demanda de ejecución provisional».

${ }^{26} \mathrm{El}$ artículo 723.2 LEC establece que «para conocer de las solicitudes relativas a medidas cautelares que se formulen durante la sustanciación de la segunda instancia o de un recurso extraordinario por infracción procesal o de casación, será competente el Tribunal que conozca de la segunda instancia o de dichos recursos». De otro lado, en virtud de lo previsto en el artículo 730.4 LEC, «pendiente recurso sólo podrá solicitarse la adopción de medidas cautelares cuando la petición se base en hechos y circunstancias que justifiquen la solicitud en esos momentos». 


\section{II.3. Las demandas que, por estado ruinoso, pretendan la demolición de una obra}

El tradicional «interdicto de obra ruinosa» venía regulado, como es sabido, en los artículos 1676 a1685 LEC/1881, preceptos que incluían, de un lado, normas dirigidas a la adopción de medidas de aseguramiento de la obra y, de otro, normas relativas a la condena a la demolición de la obra que amenazase ruina.

Estas normas, sin embargo, fueron limitadas por la vigente $\mathrm{LEC}^{27}$, de tal manera que en la actualidad, de conformidad con lo establecido en el artículo 250.1.6 ${ }^{\circ}$ LEC, se decidirán en juicio verbal, cualquiera que sea su cuantía, las demandas «que pretendan que el tribunal resuelva, con carácter sumario, la demolición o derribo de obra, edificio, árbol, columna o cualquier otro objeto análogo en estado de ruina y que amenace causar daños a quien demande».

Ello no obstante, las «medidas urgentes de precaución», esto es, las dirigidas a evitar los riesgos derivados del mal estado en que se encuentre alguna cosa y, cuya caída pudiera causar daños, podrán ser solicitadas como medidas cautelares asegurativas de adopción urgente, de conformidad con los artículos 728 y ss LEC ${ }^{28}$. Estas medidas, en caso de ser estimadas serán ejecutadas de manera definitiva $^{29}$.

En lo que respecta tanto a los medios de impugnación, como a la ejecución de la sentencia dictada en estos procesos, el legislador, al igual que en los supuestos analizados anteriormente, tampoco ha previsto especialidad procesal alguna, de donde se infiere que resultará de aplicación el régimen ordinario y, por tanto, de un lado, cabe el recurso de apelación contra la sentencia dictada y, de otro, también es posible proceder a su ejecución provisional.

\section{II.4. Las demandas que pretendan recabar la posesión de los bienes hereditarios}

De conformidad con lo dispuesto en el artículo 250.1.3 $3^{\circ} \mathrm{LEC}$, se decidirán en juicio verbal, cualquiera que sea su cuantía, las demandas «que pretendan que el tribunal ponga en posesión de bienes a quie-

27 Vid. GIMENO SENDRA V., Derecho Procesal Civil..., op. cit., p. 107; ARMENTA DEU, La ejecución provisional, op. cit., p. 149.

${ }^{28}$ Cfr. GIMENO SENDRA, V., Derecho Procesal Civil..., op. cit., p. 108.

29 Cfr. ARMENTA DEU, La ejecución provisional, op. cit., p. 149. 
nes los hubiere adquirido por herencia si no estuvieren siendo poseídos por nadie a título de dueño o usufructuario».

Este proceso, heredero del antiguo procedimiento incidental para recabar la posesión de los bienes hereditarios, tiene como objeto la pretensión de que el actor sea puesto judicialmente en la posesión de los bienes que hubiere adquirido por herencia, luego de acreditar su título hereditario y, que la cosa no está siendo poseída por nadie a título de dueño, ni usufructuario y, de permitir a los oponentes que se crean con mejor derecho comparecer en el proceso para oponerse a la pretensión ${ }^{30}$.

La característica especial de este concreto proceso, con respecto a las normas comunes del juicio verbal es la relativa a la introducción, en virtud del artículo 441.1 LEC, de una fase previa, sumarísima, dirigida a otorgar la posesión del bien, una vez que se hayan acretitado los presupuestos o requisitos legales ${ }^{31}$, para, a continuación, proceder a la llamada al proceso de aquellos poseedores reales del bien o bienes concretos, para que se pueda proceder a debatir su oposición a la pretensión deducida ${ }^{32}$.

Ello no obstante, si la sentencia dictada estima la pretensión planteada, habida cuenta que las especialidades previstas para estos pro$\operatorname{cesos}^{33}$, no afectan ni al régimen de los recursos ni al de de ejecución provisional, al igual que en los procesos anteriormente citados, el régimen establecido para la ejecución provisional en los artículos 524 y ss. LEC, resulta sin duda aplicable a las sentencias dictadas en este concreto proceso ${ }^{34}$.

${ }^{30}$ Cfr. GIMENO SENDRA, V., Derecho Procesal Civil. Tomo II. Los procesos especiales, op. cit., p. 112.

31 La competencia para realizar el llamamiento previsto en el artículo 441.1 LEC corresponde al Secretario Judicial, tras la entrada en vigor de la Ley 13/2009, de 3 de noviembre, de reforma de la legislación procesal para la implantación de la nueva Oficina judicial.

$32 \mathrm{Al}$ respecto señala GIMENO que «se mantiene, pues, la estructura del antiguo interdicto de adquirir, con sus fases "sumarísima» y "sumaria», que le confiere su naturaleza de proceso "posesorio-provocatorio» pues su finalidad es excitar a los posibles oponentes a mostrarse parte en el proceso y hacer su reclamación $<<$ si consideran tener mejor derecho que el demandante >> (art. 441.1.I in fine) frente a la posesión provisionalmente otorgada» Cfr. GIMENO SENDRA, V., Derecho Procesal Civil. Tomo II. Los procesos especiales, op. cit., pp. 116-117.

33 Vid. Artículos 266.4 y 441.1 LEC

34 Vid. en este sentido ARMENTA DEU, La ejecución provisional, op. cit., p. 150. 


\section{EL PROCEDIMIENTO PARA LA PROTECCIÓN REGISTRAL DE LOS DERECHOS REALES INSCRITOS}

El antiguo procedimiento para salvaguardar la protección registral de los derechos reales inscritos en el Registro de la Propiedad, creado por el artículo 41 de la Ley Hipotecaria, de 8 de febrero de 1946 y, cuya redacción fue modificada por la Disposición Final $9^{\mathrm{a}} \mathrm{LEC}^{35}$, figura en la actualidad incluido en el ámbito del juicio verbal, en virtud de lo establecido en el artículo 250.1.7 ${ }^{\circ}$ LEC, relativo a las demandas «que, instadas por los titulares de derechos reales inscritos en el Registro de la Propiedad, demanden la efectividad de esos derechos frente a quienes se opongan a ellos o perturben su ejercicio, sin disponer de título inscrito que legitime la oposición o la perturbación» ${ }^{36}$.

35 En virtud de dicha modificación, el contenido del artículo 41 LH es el siguiente: «Las acciones reales procedentes de los derechos inscritos podrán ejercitarse a través del juicio verbal regulado en la Ley de Enjuiciamiento Civil, contra quienes, sin título inscrito, se opongan a aquellos derechos o perturben su ejercicio. Estas acciones, basadas en la legitimación registral que reconoce el artículo 38, exigirán siempre que por certificación del Registrador se acredite la vigencia, sin contradicción alguna, del asiento correspondiente».

36 Sobre este proceso, la jurisprudencia menor ha señalado reiteradamente que «sobre el procedimiento antes denominado del artículo $41 \mathrm{LH}$, hoy previsto en el articulo 250.1.7 ${ }^{\circ}$ LEC ha habido abundante jurisprudencia sobre todo menor y así es sabido, que el procedimiento para la protección de los derechos reales inscritos del artículo 41 LH que se tramita hoy por el cauce del juicio verbal a tenor de lo dispuesto en el artículo 250.1.7 $L E C$, tras la modificación operada en el precitado artículo 41 por la Disposición Final $9^{a}$ de la LEC es un proceso declarativo especial y sumario que tiene por finalidad la efectividad de las acciones reales que dimanen de los derechos inmobiliarios inscritos, concediendo fuerza ejecutiva provisional a los asientos del Registro que quedan así equiparados a una resolución provisoria, y producen si no hay contradicción, plenos efectos ejecutivos, por lo que con su ejercicio se pretende y no es otra su finalidad, conseguir un resultado de hecho idéntico al que se lograría con la ejecución de la sentencia que se hubiera obtenido de haber ejercitado con éxito en la vía ordinaria una acción real entre las que se incluye como mas característica la reivindicatoria. La acción derivada pues del precitado artículo 41 LH no es otra cosa que una consecuencia mas del principio legitimador contenido en el art. 38 de la misma LH que presume la posesión del derecho real inscrito en favor del titular que en el asiento aparece como tal, al decir que se presume que los derechos reales inscritos existen y pertenecen a quien en ellos aparece como titular en la forma que determina el asiento respectivo, presunción iuris tantum de concordancia entre la realidad extraregistral y la registral que no impide la oposición si bien por unos motivos determinados y concretos.»

Asimismo se ha señalado que "presenta un carácter especial, singular y expeditivo, orientado a la protección de los derechos reales inscritos, en tanto que consecuencia de la fuerza legitimadora del Registro de la Propiedad, al presumirse concordantes Registro y realidad, en el sentido de que el derecho inscrito existe y pertenece a su titular en la forma determinada en el asiento respectivo, al extremo de que, para contradecir esta concordancia, deberá formularse oposición con base en alguna o algunas de las causas taxativamente contempladas en la Ley, cuya prueba incumbe al contradictor.»Cfr. entre 
Junto al citado precepto han de tenerse en cuenta las múltiples especialidades procedimentales previstas a lo largo de la LEC, las cuales recogen una parte importante de las disposiciones del anterior artículo $41 \mathrm{LH}$. Concretamente, figuran recogidas previsiones específicas en relación con los siguientes aspectos: inadmisión de la demanda (artículo 439.2 LEC); citación para la vista (artículo 440.2 LEC); medidas cautelares (artículo 441.3 LEC); contenido de la vista (artículo 444.2 LEC); y ausencia de cosa juzgada (artículo 447.3 LEC).

En lo que respecta a la admisión de la demanda, ha de tenerse en cuanta que viene condicionada al previo cumplimiento de los siguientes requisitos: en primer lugar, debe expresar concretamente las medidas que se consideren necesarias para asegurar la eficacia de la sentencia que recayere; en segundo, el demandante ha de optar, bien por señalar la caución que debe prestar el demandado, en caso de comparecer y contestar, para responder de los frutos percibidos percibido indebidamente, de los daños y perjuicios causados, así como de las costas del proceso, o bien por renunciar expresamente a ello; y, por último, a la demanda se acompañará una certificación literal del Registro de la Propiedad, que acredite expresamente la vigencia, sin contradicción alguna, del asiento en el que el demandante legitima su posición.

De entre todas las especialidades citadas, merece un lugar destacado, igualmente el contenido del artículo 440.2 LEC, en cuya virtud, tanto en el supuesto de incomparecencia del demandado a la vista, como si una vez comparecido no procede a prestar la caución determinada por el juzgador, el Juez dictará sentencia acordando las actuaciones que hubieran sido solicitadas por el demandante, para la efectividad del derecho inscrito. En otro caso, el proceso continuará por las normas del juicio verbal.

Una vez más y, al igual que se ha analizado en relación con las materias objeto de los «interdictos», las especialidades procesales recogidas por el legislador en relación con esta concreta materia, no hacen referencia ni a los medios de impugnación, ni a la ejecución, de lo que se infiere que, también en este supuesto, resultarán de aplicación las disposiciones generales sobre ambas materias.

otras, Sentencias de la Audiencia Provincial de Málaga (Sección 4a), Sentencia núm. 177/2008, de 31 marzo, AC 2008\1335, Fundamento de Derecho Tercero; y de 31 de julio de 2007, de la Audiencia Provincial de Granada (Sección 4ª), Sentencia núm. 128/2005, de 1 marzo, AC\2005\1011, Fundamento de Derecho Primero. 
Por tanto, las sentencias que puedan recaer en estos procesos podrán ser recurridas en apelación y, en el supuesto de tratarse de una sentencia estimatoria, igualmente será susceptible de ejecución provisional, ejecución que se someterá a las reglas generales de los artículos 524 y ss LEC, esto es, siempre que contenga un pronunciamiento condenatorio. Por el contrario, la sentencia que desestime la demanda y, en su caso, deje sin efecto las medidas de aseguramiento que puedan haberse adoptado, no será objeto de ejecución provisional, sino, en su caso de ejecución ordinaria, por carecer de efectos suspensivos el recurso contra ella interpuesto, «ex» artículo 456.2 LEC.

\section{CONCLUSIONES}

Las consideraciones anteriores permiten afirmar que, con carácter general, el tipo de procedimiento judicial en que una determinada resolución haya sido dictada, no influirá en la decisión en torno a su posible ejecución provisional, en la medida en que las normas reguladoras de la ejecución provisional no establecen previsión alguna al respecto.

De manera específica, en relación con las sentencias dictadas en los procesos previstos en el artículo 250.1 LEC para la protección de la posesión, esto es, los denominadas «interdictos», así como respecto de las dictadas en el procedimiento para la protección registral de los derechos reales inscritos, previsto en el artículo 250.1.7 $7^{\circ}$ LEC, en relación con el artículo $41 \mathrm{LH}$, habida cuenta que las especialidades procesales previstas para tales procesos tampoco hacen mención alguna a su posible ejecución provisional, serán, como se ha señalado, el tipo y el contenido de la resolución dictada los que permitan aceptar o denegar la aplicación del régimen de ejecución provisional previsto en los artículos 524 y ss LEC a las sentencias en ellos dictadas.

Por consiguiente, puede afirmarse que las sentencias dictadas tras un proceso declarativo llevado a cabo por las normas del juicio verbal, con base en una demanda que pretenda retener o recobrar la posesión, la demolición de una obra por su estado ruinoso, recobrar la posesión de los bienes hereditarios o la protección registral de los derechos reales inscritos, son, en principio, susceptibles de ejecución provisional conforme al régimen establecido en los artículos 524 a 537 LEC.

Sin embargo, aquellas sentencias que estimen la pretensión dirigida a obtener la suspensión de una obra nueva, aún cuando, desde 
un punto de vista teórico, no exista impedimento legal alguno, en la práctica el actor no necesitará instar la ejecución provisional de la condena obtenida, en la medida en que tal suspensión generalmente habrá sido adoptada con carácter cautelar desde el inicio del procedimiento. 